Article

\title{
Incentive Mechanism of Prefabrication in Mega Projects with Reputational Concerns
}

\author{
Qianqian Shi ${ }^{1}{ }^{(\mathbb{D}}$, Jianbo Zhu ${ }^{1, *}$, Marcel Hertogh ${ }^{2}$ and Zhaohan Sheng ${ }^{1}$ \\ 1 School of Management and Engineering, Nanjing University, Nanjing 210093, China; \\ qqs1991@126.com (Q.S.); zhsheng@nju.edu.cn (Z.S.) \\ 2 Faculty of Civil Engineering and Geosciences, Delft University of Technology, Stevinweg 1, 2628 CN Delft, \\ The Netherlands; M.J.C.M.Hertogh@tudelft.nl \\ * Correspondence: zhujianbowss@163.com; Tel.: +86-139-1394-4930
}

Received: 19 March 2018; Accepted: 13 April 2018; Published: 19 April 2018

\begin{abstract}
As one of the most important sustainability project management practices, prefabrication has been drawing increasing attention to project construction practitioners. However, due to the needs of high technology and large capital investment, there is a great challenge for suppliers to adopt prefabrication in mega project construction. Therefore, designing an adequate incentive mechanism has become a daunting task for the project owner, which aims to ensure a socially and environmentally friendly project delivery. In this study, an incentive model with reputational concerns from the perspective of the project owner was established and how this incentive affects supplier's effort and project owner's profit was investigated. By contrasting to the incentive model without reputational concerns, when the reputation incentive is considered in the incentive contract, both supplier's effort and project owner's profit increase. In addition, adding reputation incentive implies more expenses, thus the project owner may not want to take this strategy due to the potential expense increase. Therefore, the study also considered an incentive mechanism with constant total incentive intensity. By comparison, the result shows that this strategy is also useful which can improve supplier's effort and project owner's profit.
\end{abstract}

Keywords: prefabricated construction; incentive mechanism; reputation; sustainability management practice

\section{Introduction}

In recent years, due to the needs of urbanization and economic development, increasing attention has been drawn to the construction of mega projects. Mega projects have the characteristics of high technical difficulty, quality requirement, knowledge intensive, and capital and sustainable development demand, which has brought great complexity to mega project construction [1-3]. However, on the one hand, it is difficult for suppliers to meet the requirements of duration and quality by relying on traditional technology and knowledge, especially in regard to the production of key parts and components in mega projects at the building site. On the other hand, sustainability is becoming increasingly important in the delivery of projects, as it has been concerned with as a project goal and might have substantial impact economically, socially and environmentally [4]. Prefabrication within mega project construction and industrialized construction can improve both short-term efficiency and long-term innovation and sustainability, which is one of the most important means of sustainability project management practices $[5,6]$. Therefore, prefabrication has become the main manufacturing method adopted by suppliers in mega project construction.

Prefabrication is a construction operation approach that produces key components of the project in a professional factory or other manufacturing site in a standardized and controlled process, transports 
complete assemblies to the construction site and assembles them [7,8]. Effective implementation of prefabrication strategies could obtain stable quality, accurate production schedule control, significant cost savings and significant environmental, economic and social benefits [9-11]. Therefore, the owners of mega projects usually prefer to adopt the prefabrication method. Although the merits of prefabrication have been considerably recognized for requirements of urbanization and sustainability demand, the art of prefabrication in infrastructure construction industry is in its early stages of development, the level of professionalization is immature, and there are great barriers for suppliers to enter and invest more resources in prefabrication process [12]. Hong et al. [13] explored that economic benefit is a key concern for stakeholders to be involved in prefabrication production based on a cost-benefit analysis. Other researchers also found that higher cost increased the reluctance to adopt prefabrication method and invest more resources in this process through questionnaire survey and case study [12,14]. Specifically, Mao et al. [15] revealed that the incremental cost of prefabrication has been estimated as higher than conventional on-site construction by $27-109 \%$. Through investigation, the additional cost of prefabrication derives from the high initial investment (such as new professional machinery, fabrication molds, and factories), innovative technology, design changes and transportation cost $[13,16]$. Besides, technology innovation complexity, lack of standards and specifications, long lead-in times, and lack of knowledge and understanding are all the obstacles for practitioners in prefabrication mode $[12,17,18]$.

Furthermore, from the perspective of prefabrication practices in mega projects, besides the higher cost, difficult technical requirements, high quality standards, large project quantities, tight schedule, and limited industry resources all increase the complexity of prefabrication. For example, prefabrication is adopted in the manufacture of the steel box girder of the Hong Kong-Zhuhai-Macao Bridge. In total, 0.425 million ton steel should be manufactured and provided within three years, while the service life needs to reach 120 years. However, the suppliers in prefabrication market who own the capability to provide such high quantity and quality of products are lacking. The owners of the Hong Kong-Zhuhai-Macao Bridge need to seek for the potential suppliers who can provide the products and make these suppliers meet the requirements through supplier development and its incentives [19]. For example, there is a large gap between the capability of Wuchang Shipbuilding Industry Group Co., Ltd. (Wuhan, China) and the owner's requirements, therefore appropriate incentives should be introduced for the project owner to improve its motivation to update equipment, $R \& D$ technology, education and training, to improve prefabrication performance and implement the supplier development in mega projects. As a result, incentive mechanisms are necessary and should be established by the project owner to motivate the suppliers to invest more resources and efforts into the prefabricated production and achieve ethicality, eco-friendliness, and economic efficiency.

Considering the great influence of mega projects in our society and industry, it will have a significant influence on suppliers to participate in mega project construction which could formulate their better reputations. The reputation of the supplier is a comprehensive evaluation on the combination of brand, performance, industry status and social responsibility via a set of criteria [20]. Favorable reputation could not only make the prefabrication suppliers have advantages during the bidding stage, but also obtain more incentive benefits in the process of cooperation and improve their future competitiveness in the market [21]. Therefore, incentives with reputational concerns not only attract well-established suppliers to participate in the construction of the mega project, but also better promote the suppliers to improve their reputations and adopt a higher degree of prefabrication which could greatly influence project output. How to design the incentive mechanism of prefabrication in mega projects with reputational concerns is one of the most important clauses to the output of the mega project and supplier cultivation and development. 


\section{Literature Review}

\subsection{Sustainability in Project Management}

In addition to the iron triangle of time, cost, and quality, sustainability is getting increasing attention on project management. Many scholars considered that sustainability integrated with project management is an emerging field [22-25], which includes a lot of research from different perspectives. The significant impacts of sustainability on project management are highlighted by Silvius [26]: project management gradually shifted from managing cost, time and quality to managing social, environmental, and economic impact, as well as project managers are willing to take more responsibility for the role of sustainability management in the decision making process, when comparing with conventional project management. Silvius et al. [27] also investigated the consideration of sustainability aspects in the decision making processes of project managers. Martens and Carvalho [28] identified and explained the variables and key factors on sustainability in project management from the project managers' perspective. Marcelino-Sádaba et al. [29] established a conceptual framework to manage sustainable projects and identified four pillars: product, processes, organization and managers. Sustainability practices in project management have also been paid attention to by many scholars, such as lean production, life-cycle management, waste management systems, prefabrication, etc. $[8,30,31]$. Prefabrication has been viewed as an important means that improves the sustainable construction of mega projects by alleviating environmental risks compared to traditional construction [32]. Several researchers have studied the technology and methods to increase the performance of prefabrication, such as simulation modeling and optimization techniques [33,34]. Chen et al. [8] compared prefabrication and on-site construction method comprehensively and identified a list of holistic criteria for assessment and assisting construction practitioners in selecting the appropriate construction methods. Shi et al. [35] and Feng et al. [36] explored the cooperation tendency of prefabricated producers by considering incentive mechanism in mega projects. Wu et al. [37] developed an incentive model to analyze the cooperative relationship between owners and contractors in sustainable construction projects. However, how to encourage suppliers to adopt and improve prefabrication construction practices from project managers' perspective during early project stages is also an important topic, which still needs to be further investigated.

\subsection{Incentive Mechanism in Project Management}

Appropriate incentive mechanisms can encourage suppliers to select prefabrication construction method and motivate them to invest more resources and efforts and achieve sustainability development. In recent years, the importance of research on incentive mechanisms has received increasing attention from the project construction researchers and practitioners [38]. They conduct research from several aspects.

The first aspect is verifying the effectiveness of the incentive mechanism by using different methods. Suprapto et al. [39] pointed out that projects with incentive contracts were likely to perform better than those without incentive contracts through better relational attitudes by using partial least square structural equation modeling to analyze a sample of 113 capital projects. Kerkhove and Vanhoucke [40] designed an incentive contract from the owner's perspective, and the analysis showed that the contracts which account for cost, duration and scope by using nonlinear and piecewise linear is useful to the performance of projects. Rose and Manley [41] regarded the use of incentives as key promoters of improving project performance by adopting a qualitative multiple case study methodology. Similarly, Love et al. [42] designed a risk/reward model and found that a successful project outcome could be obtained when project participants' behaviors are aligned through the use of incentives.

The second aspect is designing different incentive contracts in projects from different incentive goals, e.g., time, cost and quality incentives. For example, Dharma et al. [43] designed a duration-based incentive contract under the outsourcing situations. Chan et al. [44] analyzed how to coordinate the 
benefit between owner and contractor through a target cost contract. Karle et al. [45] evaluated the relationship between quality and incentives. In addition to being used individually, these different incentive goals could also be used collectively. Hosseinian [46] proposed a solution to the optimal sharing of multiple project outcomes, such as cost, time, quality and safety, contributed to knowledge on incentive contracts in construction. Furthermore, different payment methods in incentive contracts have been highlighted by many researchers, e.g., fixed price, cost plus fee, target cost, and payment based on performance [38]. Cost-plus incentives and performance incentives are widely recognized as two typical construction incentive contracts [47].

The third aspect is developing an optimal incentive mechanism under different circumstances. Rose and Manley [48] emphasized that contractors were more likely to be positively motivated when fair and exceptional reward were considered in the incentive system. Fu et al. [49] evaluated how agency conflicts, free-rider effects, and monitoring costs affect optimal incentive contracts. Sommer and Loch [50] developed an incentive contract in projects with unforeseeable uncertainty and offered a theoretical prediction which incentive structure was suitable for each circumstance. Tang et al. [51] examined and compared two types of time-related incentive project management contracts. Yang et al. [52] analyzed the effect of information asymmetry on a duration-base incentive contract.

\subsection{Reputation Incentives}

Recently, some researchers have pointed out the importance of reputation on incentive mechanisms. Reputation was firstly introduced by Fama [53], then Kreps, Milgrom, Roberts and Wilson established KMRW reputation model based on repeated game [54-56]. Afterwards, studies on reputation have been conducted in many aspects. Healy [57] emphasized the prediction function of reputation in a repeated cooperation market. Chi and Hou [58] considered both ability reputation and cooperation reputation of incentive mechanism in project team members by using multiple methods. Huang et al. [59] investigated a mathematical model of communication with reputational concerns where an expert provided a suggestion for two periods. Wagner et al. [60] and Lu et al. [61] explicitly pointed out that suppliers' reputation was important to the future relationship and collaboration between the owner and the supplier. Therefore, as project construction becomes more and more complicated, incentive mechanism design gradually transforms from considering explicit effort/benefit incentives only to the mechanism which combines consideration of explicit effort/benefit incentives and implicit reputation incentives [62,63].

Although previous studies contribute to a wide recognition of the importance of reputation and incentive, there also exist limitations within these studies. First, previous studies rarely investigated reputation incentives from the perspective of mathematical modeling. Therefore, it is hard to find the relationship between important influence factors and reputation incentives and give advice on how to adjust these parameters. Secondly, most studies only used market recognition to define supplier's reputation, without considering the influence of suppliers' effort. Thirdly, there is a lack of consideration that the owner of the project is irrational: What if the owner does not want to improve the incentive intensity and pay more to the supplier? Finally, designing and selecting most adequate reputation incentive mechanism for prefabricated suppliers has become a daunting task for project owners, but most of previous studies did addressed the problem from the perspective of the owner.

As mentioned above, an incentive mechanism with reputational concerns would have a significant effect on the improvement of suppliers' effort as well as the prefabrication quality of mega projects. The goal of this study was to provide a quantitative framework for reputation incentive mechanism of prefabrication in mega project, which helps the project owner to design most adequate incentive mechanism and implement supplier cultivation and sustainability objectives. Therefore, to overcome the limitations mentioned above, three incentive mechanisms are discussed in this paper, which is organized as follows. First, a model of explicit incentive without reputational concerns is designed and solved. Then, an incentive model with reputational concerns from the perspective of the owner is 
established and how the incentive affects suppliers' effort and project owner's profit is investigated, followed by discussions of the model. Furthermore, the project owner is assumed to be irrational, a situation that the incentive intensity is kept the same but a portion of it is reallocated to reputation is considered, and then followed by comparison. Numerical analysis is provided in this paper for further understanding. Finally, conclusions with some summary findings are presented.

\section{Model Description, Solution and Analysis}

In mega projects, the owner, as a principal, needs to delegate suppliers to provide the key components, such as steel box girder. Due to the product's particularity and production capacity limitations, only few suppliers are chosen to provide this product. Therefore, in our model, we assumed one owner and one supplier. The supplier, as an agent, usually supplies the needed products to the owner through professional manufacturing. To stimulate the supplier to be willing to participate and invest more resources and efforts into prefabricated production and improve the supplied product quality and sustainability performance, the project owner designs an adequate incentive mechanism to ensure the investment of the supplier is achievable and the project performance is reached. The supplier usually tries to find the optimal level of effort to ensure its own maximum return. The interests of the project owner and those of supplier are generally not consistent. The principal-agent model in game theory is considered in our model.

The basic notations are as follows:

e: The productive effort of the supplier, implies the equipment, labors and other resources which are invested by the supplier.

r: The observed reputation of the supplier in production process, represents the aptitude and capacity of the supplier, where higher reputation means faster implementation and optimization of natural resources, reducing waste and minimizing risks for the worker, etc.

$\mathrm{x}$ : The observable variable of supplier's effort, which could be observed by duration and quality of the product.

$\mathrm{k}$ : The effort coefficient of the supplier, $\mathrm{k} \in[0,+\infty)$.

$\lambda: \quad$ The reputation coefficient of the supplier, $\lambda \in[0,+\infty)$.

$\varepsilon$ : An exogenous random variable which influences the output, such as the uncertainty of the market, technology and environment, i.e., $\varepsilon \sim \mathrm{N}\left(0, \sigma_{\varepsilon}^{2}\right)$.

$\varepsilon_{1}$ : An external random variable which influences the observable variable of the effort, $\varepsilon_{1} \sim \mathrm{N}\left(0, \sigma_{1}^{2}\right)$.

$r_{0}$ : The initial market evaluation value of the supplier's reputation, represents the aptitude and capacity of the supplier that evaluated by the project owner in the bidding stage.

$e_{0}$ : The basic standard value of productive effort.

$a$ : The effort coefficient of the reputation, $a \in(0,+\infty)$.

$\varepsilon_{2}$ : An external random variable which influences reputation function, $\varepsilon_{2} \sim \mathrm{N}\left(0, \sigma_{2}^{2}\right)$.

$\mu: \quad$ The cost coefficient of the supplier, $\mu>0$.

$\bar{w}$ : The fixed pay in the contract.

$\beta_{e}$ : The marginal incentive intensity of the effort.

$\beta_{r}$ : The marginal incentive intensity of the reputation.

$\bar{w}^{\prime}$ : The reservation utility of the supplier.

$\mathrm{m}$ : The total output of the production.

C: The supplier's production cost, which can be expressed as $\mathrm{C}=\frac{1}{2} \mu e^{2}$, the cost function conform to properties of increasing cost and increasing marginal cost, which is $\partial C(e) / \partial e>0, \partial^{2} C(e) / \partial e^{2}>0$.

$\mathrm{U}: \quad$ The expected payoff of the owner.

V: The expected payoff of the supplier.

Here, we assume that the project owner is risk-neutral, while the supplier is risk averse, with a risk evasion coefficient of $\rho, \rho>0$. 


\subsection{Incentive Mechanism without Reputational Concerns}

We assume that the project owner and the supplier are fully rational and independent, the same as the starting-point of many other studies. An incentive model without reputational concerns is discussed as a reference in this section.

Under this circumstance, the output function can be expressed as $m_{1}=k e_{1}+\varepsilon$, while the incentive contract can be expressed as $\mathrm{W}_{1}=\bar{w}+\beta_{e 1} x_{1}$.

Therefore, the incentive of the supplier which only considers level of productive effort is equivalent to solving the following constrained programming problem:

$$
\begin{gathered}
\max _{\bar{w}, \beta_{e 1}} \mathrm{U}_{1}=k e_{1}-\bar{w}-\beta_{e 1} e_{1} \\
\text { s.t. }\left\{\begin{array}{c}
(I R) \bar{w}+\beta_{e 1} e_{1}-\frac{1}{2} \mu e_{1}^{2}-\frac{1}{2} \rho \beta_{e 1}^{2} \sigma_{1}^{2} \geq \bar{w}^{\prime} \\
(I C) e_{1} \in \operatorname{argmax}\left(\bar{w}+\beta_{e 1} e_{1}-\frac{1}{2} \mu e_{1}^{2}-\frac{1}{2} \rho \beta_{e 1}^{2} \sigma_{1}^{2}\right)
\end{array}\right.
\end{gathered}
$$

According to the first-order optimal solutions to Equations (1) and (2), the optimal incentive intensity of the effort, the optimal level of productive effort of the supplier, and the optimal profit of the project owner, respectively, are:

$$
\begin{gathered}
\beta_{e 1}^{*}=\frac{k}{1+\rho \mu \sigma_{1}^{2}} \\
e_{1}^{*}=\frac{k}{\mu\left(1+\rho \mu \sigma_{1}^{2}\right)} \\
U_{1}^{*}=\frac{k^{2}}{2 \mu\left(1+\rho \mu \sigma_{1}^{2}\right)}-\bar{w}^{\prime}
\end{gathered}
$$

\subsection{Incentive Mechanism with Reputational Concerns}

In this section, we consider the incentive mechanism with reputational concerns. Under this circumstance, the output function can be expressed as $m_{2}=k e_{2}+\lambda r+\varepsilon$, while, based on the research of Wagner et al. [60], the supplier's reputation can be expressed as $r=r_{0}+a\left(e-e_{0}\right)+\varepsilon_{2}$. The incentive contract can be expressed as $W_{2}=\bar{w}+\beta_{e 2} x_{2}+\beta_{r 2} r$.

Therefore, the expected payoff of the owner is:

$$
U_{2}=k e_{2}+\lambda r-\bar{w}-\beta_{e 2} e_{2}-\beta_{r 2} r
$$

The expected payoff of the supplier is:

$$
V_{2}=\bar{w}+\beta_{e 2} e_{2}+\beta_{r 2} r-\frac{1}{2} \mu e_{2}^{2}-\frac{1}{2} \rho\left(\beta_{e 2}^{2} \sigma_{1}^{2}+\beta_{r 2}^{2} \sigma_{2}^{2}\right)
$$

Therefore, the incentive of the supplier which considers both reputation and effort is equivalent to solving the following constrained programming problem:

$$
\begin{gathered}
\max _{\bar{w}, \beta_{e 2}, \beta_{r 2}} \mathrm{U}_{2}=k e_{2}+\lambda r-\bar{w}-\beta_{e 2} e_{2}-\beta_{r 2} r \\
\text { s.t. }\left\{\begin{array}{c}
(I R) \bar{w}+\beta_{e 2} e_{2}+\beta_{r 2} r-\frac{1}{2} \mu e_{2}^{2}-\frac{1}{2} \rho\left(\beta_{e 2}^{2} \sigma_{1}^{2}+\beta_{r 2}^{2} \sigma_{2}^{2}\right) \geq \bar{w}^{\prime} \\
(I C) e_{2} \in \operatorname{argmax}\left(\bar{w}+\beta_{e 2} e_{2}+\beta_{r 2} r-\frac{1}{2} \mu e_{2}^{2}-\frac{1}{2} \rho\left(\beta_{e 2}^{2} \sigma_{1}^{2}+\beta_{r 2}^{2} \sigma_{2}^{2}\right)\right)
\end{array}\right.
\end{gathered}
$$

According to the first-order optimal solutions to Equations (8) and (9), the optimal incentive intensity of the effort and the reputation, the optimal level of productive effort of the supplier, and the optimal profit of the project owner, respectively, are: 


$$
\begin{gathered}
\beta_{e 2}^{*}=\frac{\sigma_{2}^{2}(k+\lambda a)}{\rho \mu \sigma_{1}^{2} \sigma_{2}^{2}+a^{2} \sigma_{1}^{2}+\sigma_{2}^{2}} \\
\beta_{r 2}^{*}=\frac{a \sigma_{2}^{2}(k+\lambda a)}{\rho \mu \sigma_{1}^{2} \sigma_{2}^{2}+a^{2} \sigma_{1}^{2}+\sigma_{2}^{2}} \\
e_{2}^{*}=\frac{\left(a^{2} \sigma_{1}^{2}+\sigma_{2}^{2}\right)(k+\lambda a)}{\mu\left(\rho \mu \sigma_{1}^{2} \sigma_{2}^{2}+a^{2} \sigma_{1}^{2}+\sigma_{2}^{2}\right)} \\
U_{2}^{*}=\frac{\left(a^{2} \sigma_{1}^{2}+\sigma_{2}^{2}\right)(k+\lambda a)^{2}}{2 \mu\left(\rho \mu \sigma_{1}^{2} \sigma_{2}^{2}+a^{2} \sigma_{1}^{2}+\sigma_{2}^{2}\right)}+\lambda\left(r_{0}-a e_{0}\right)-\bar{w}^{\prime}
\end{gathered}
$$

From the solution, we can draw some important conclusions.

Proposition 1. The incentive intensity is not only closely related to the variance of the incentive target itself, but is also influenced by the variance of another incentive target. The larger is the variance of the incentive target, the lower is the incentive intensity of such incentive target. On the contrary, the larger is the variance of another incentive target, the larger is the incentive intensity of this incentive target.

Confirmation: $\partial \beta_{e 2}^{*} / \partial \sigma_{1}^{2} \leq 0, \partial \beta_{e 2}^{*} / \partial \sigma_{2}^{2} \geq 0, \partial \beta_{r 2}^{*} / \partial \sigma_{1}^{2} \geq 0, \partial \beta_{r 2}^{*} / \partial \sigma_{2}^{2} \leq 0$.

The conclusion is in accordance with intuition. For example, when $\sigma_{2}^{2}$ is larger, this means the uncertainty of reputation evaluation is larger, thus the information asymmetry between the project owner and the supplier will increase, which leads to a smaller incentive intensity on reputation that the project owner wants to provide. In addition, when $\sigma_{1}^{2}$ is larger, this means the observability of supplier's effort is smaller, then compared to the supplier's effort, and the project owner will be more convinced about their judgement on supplier's reputation, which leads them to provide a larger incentive intensity on reputation.

Proposition 2. When the reservation utility of the supplier $\left(\bar{w}^{\prime}\right)$ remains constant, the level of productive effort of the supplier $\left(e_{2}\right)$ and the profit of the project owner $\left(U_{2}\right)$ is correlated positively with the effort coefficient $(k)$ and the reputation coefficient $(\lambda)$; negatively with the cost coefficient $(\mu)$ and the risk evasion coefficient $(\rho)$; and negatively with the variance of the incentive target $\left(\sigma_{1}^{2}, \sigma_{2}^{2}\right)$.

Confirmation: Using the level of productive effort of the supplier as an example, while the profit of the project owner is the same: $\partial e_{2}^{*} / \partial \sigma_{1}^{2} \leq 0, \partial e_{2}^{*} / \partial \sigma_{2}^{2} \leq 0, \partial e_{2}^{*} / \partial k \geq 0, \partial e_{2}^{*} / \partial \lambda \geq 0, \partial e_{2}^{*} / \partial \mu \leq 0$, $\partial e_{2}^{*} / \partial \rho \leq 0$.

From the management meaning, when the uncertainty of the profitability decreases, the output capacity improves, or the effort cost reduces, the suppliers intend to improve their productive effort level, thereby the project owner is more willing to improve the incentive intensity, which will prompt the project owner to obtain higher profit. In addition, the project owner is more willing to improve the incentive intensity on those suppliers with smaller risk evasion degrees. The reason is that those suppliers are likely to improve their productive effort levels when they are not afraid of the risk, which could also help the project owner to obtain a higher profit.

Proposition 3. In regard to the supplier with lower cost coefficient, the decrease in the uncertainty of supplier's reputation evaluation helps to increase the project owner's profit.

$$
\text { Confirmation: }-\frac{\partial^{2} U_{2}^{*}}{\partial \sigma_{2}^{2} \partial \mu}=-\frac{\rho^{2} a^{2} \sigma_{1}^{6} \sigma_{2}^{2}(k+\lambda a)^{2}}{\rho \mu \sigma_{1}^{2} \sigma_{2}^{2}+a^{2} \sigma_{1}^{2}+\sigma_{2}^{2}} \leq 0
$$


$-\partial^{2} U_{2}^{*} / \partial \sigma_{2}^{2}$ represents the improvement of the project owner's marginal profit affected by the decreased uncertainty of the reputation evaluation. Equation (14) proves that the effect of the uncertainty of the reputation evaluation on the project owner's profit improvement increases with the decreased cost coefficient.

Proposition 4. When the risk evasion coefficient $\rho$ belongs to the interval $\left(0, \rho^{*}\right)$, the profit that the project owner obtained from the decreasing of the uncertainty of reputation evaluation increases with the increasing risk evasion coefficient. On the contrary, when the risk evasion coefficient $\rho$ belongs to the interval $\left(\rho^{*},+\infty\right)$, the profit that the project owner obtained from the decreasing of the uncertainty of reputation evaluation decreases with the increasing risk evasion coefficient. The project owner can obtain the maximum marginal profit when the risk evasion coefficient of the supplier is equals to $\rho^{*}$, and $\rho^{*}=\frac{a^{2} \sigma_{1}^{2}+\sigma_{2}^{2}}{\mu \sigma_{1}^{2} \sigma_{2}^{2}}$.

$$
\text { Confirmation: }-\frac{\partial^{2} \mathrm{U}_{2}^{*}}{\partial \sigma_{2}^{2} \partial \rho}=-\frac{\mathrm{a}^{2} \sigma_{1}^{4}(\mathrm{k}+\lambda \mathrm{a})^{2}\left[\rho \mu \sigma_{1}^{2} \sigma_{2}^{2}-\left(\mathrm{a}^{2} \sigma_{1}^{2}+\sigma_{2}^{2}\right)\right]}{2\left(\rho \mu \sigma_{1}^{2} \sigma_{2}^{2}+\mathrm{a}^{2} \sigma_{1}^{2}+\sigma_{2}^{2}\right)^{3}}
$$

Assume $\rho^{*}=\frac{a^{2} \sigma_{1}^{2}+\sigma_{2}^{2}}{\mu \sigma_{1}^{2} \sigma_{2}^{2}}$; Equation (15) proves that, when $\rho \in\left(0, \rho^{*}\right),-\frac{\partial^{2} U_{2}^{*}}{\partial \sigma_{2}^{2} \partial \rho}>0$, which also indicates that the effect of the uncertainty of reputation evaluation on the project owner's profit improvement increases with the decreased risk evasion coefficient. When $\rho \in\left(\rho^{*},+\infty\right),-\frac{\partial^{2} U_{2}^{*}}{\partial \sigma_{2}^{2} \partial \rho}<0$, which indicates that the effect of the uncertainty of reputation evaluation on the project owner's profit improvement increases with the increased risk evasion coefficient.

By comparison, the following conclusions can be drawn.

Proposition 5. When the reputation incentive is considered in the incentive contract, the total incentive intensity increases.

$$
\text { Confirmation: } \frac{\beta_{e 2}^{*}+\beta_{r 2}^{*}}{\beta_{e 1}^{*}}=\left(1+\frac{\lambda a}{k}\right)\left(1+\frac{\rho \mu a \sigma_{1}^{4}}{\rho \mu \sigma_{1}^{2} \sigma_{2}^{2}+a^{2} \sigma_{1}^{2}+\sigma_{2}^{2}}\right)>1 \text {, then we can get } \beta_{e 2}^{*}+\beta_{r 2}^{*}>\beta_{e 1}^{*} \text {. }
$$

Proposition 6. When the reputation incentive is considered in the incentive contract, the level of productive effort of the supplier increases, as well as the project owner's profit.

Confirmation: $\frac{e_{2}^{*}}{e_{1}^{*}}=\left(1+\frac{\lambda a}{k}\right)\left(1+\frac{\rho \mu a^{2} \sigma_{1}^{4}}{\rho \mu \sigma_{1}^{2} \sigma_{2}^{2}+a^{2} \sigma_{1}^{2}+\sigma_{2}^{2}}\right)>1$, then we can get $e_{2}^{*}>e_{1}^{*}$.

$$
U_{1}^{*}-U_{2}^{*}=\frac{\left(2 k \lambda a+\lambda^{2} a^{2}\right)\left(a^{2} \sigma_{1}^{2}+\sigma_{2}^{2}\right)\left(1+\rho \mu \sigma_{1}^{2}\right)+k^{2} \rho \mu a^{2} \sigma_{1}^{4}}{2 \mu\left(\rho \mu \sigma_{1}^{2} \sigma_{2}^{2}+a^{2} \sigma_{1}^{2}+\sigma_{2}^{2}\right)\left(1+\rho \mu \sigma_{1}^{2}\right)}+\lambda\left(r_{0}-a e_{0}\right)>0 \text {, then we can get } U_{1}^{*}>U_{2}^{*} .
$$

When reputation incentive is considered, the project owner's profit will increase. The reason is that the project owner can receive more information about the level of productive effort of the supplier through the information of the supplier's reputation, so that they can make better decision to improve the profit of themselves.

\subsection{Incentive Mechanism with Constant Total Incentive Intensity}

In the actual construction of mega projects, the project owner is not fully rational. They may act unintentionally to increase the total incentive intensity for many reasons, such as the risk of cost increase or the distrust on the supplier's reputation evaluated by the market. To solve this problem, this section discusses whether the project owner's profit increases under the incentive mechanism with constant total incentive intensity. 
Under the condition of constant total incentive intensity, the incentive of the supplier which considers both reputation and effort is equivalent to solving the following constrained programming problem:

$$
\begin{gathered}
\max _{\bar{w}, \beta_{e 3}, \beta_{r 3}} \mathrm{U}_{3}=k e_{3}+\lambda r^{\prime}-\bar{w}-\beta_{e 3} e_{3}-\beta_{r 3} r \\
\text { s.t. }\left\{\begin{array}{c}
(I R) \bar{w}+\beta_{e 3} e_{3}+\beta_{r 3} r^{\prime}-\frac{1}{2} \mu e_{3}^{2}-\frac{1}{2} \rho\left(\beta_{e 3}^{2} \sigma_{1}^{2}+\beta_{r 3}^{2} \sigma_{2}^{2}\right) \geq \bar{w}^{\prime} \\
(I C) e_{3} \in \operatorname{argmax}\left(\bar{w}+\beta_{e 3} e_{3}+\beta_{r 3} r^{\prime}-\frac{1}{2} \mu e_{3}^{2}-\frac{1}{2} \rho\left(\beta_{e 3}^{2} \sigma_{1}^{2}+\beta_{r 3}^{2} \sigma_{2}^{2}\right)\right) \\
\beta_{e 3}+\beta_{r 3} \leq C \\
r^{\prime}=r_{0}+a\left(e_{3}-e_{0}\right)+\varepsilon_{2}
\end{array}\right.
\end{gathered}
$$

where $C$ is the upper limit of the total incentive intensity, and $C$ is a constant.

In Section 3.2, the optimal total incentive intensity without the restriction of constraint condition $\beta_{e 3}+\beta_{r 3} \leq C$ has been solved:

$$
\beta^{*}=\beta_{e 2}^{*}+\beta_{r 2}^{*}=\frac{\left(a \sigma_{1}^{2}+\sigma_{2}^{2}\right)(k+\lambda a)}{\rho \mu \sigma_{1}^{2} \sigma_{2}^{2}+a^{2} \sigma_{1}^{2}+\sigma_{2}^{2}}
$$

When the upper limit of the total incentive intensity meets the condition $C>\beta^{*}$, the constrained programming problem becomes the unrestrained problem, so that the results are the same as those in Section 3.2. When the upper limit of the total incentive intensity meets the condition $C \leq \beta^{*}$, the incentive intensity constraint becomes a tight constraint in the optimal equilibrium condition, namely $\beta_{e 3}^{*}+\beta_{r 3}^{*}=C$. Substitute it into the K-T condition, in this situation, the incentive intensity of each incentive target, respectively, are: $\beta_{e 3}^{*}=\frac{C \sigma_{2}^{2}}{a \sigma_{1}^{2}+\sigma_{2}^{2}}$ and $\beta_{e 3}^{*}=\frac{C a \sigma_{1}^{2}}{a \sigma_{1}^{2}+\sigma_{2}^{2}}$.

In general, the project owner is not willing to make the total incentive intensity exceed the incentive intensity when only considering productive effort incentive, namely $C=\beta_{e 2}^{*}$. According to Proposition 5, we have $C \leq \beta^{*}$. Therefore, the optimal incentive intensity of the effort and the reputation, and the optimal profit of the project owner, respectively, are:

$$
\begin{gathered}
\beta_{e 3}^{*}=\frac{k \sigma_{2}^{2}}{\left(1+\rho \mu \sigma_{1}^{2}\right)\left(a \sigma_{1}^{2}+\sigma_{2}^{2}\right)} \\
\beta_{r 3}^{*}=\frac{k a \sigma_{1}^{2}(k+\lambda a)}{\left(1+\rho \mu \sigma_{1}^{2}\right)\left(a \sigma_{1}^{2}+\sigma_{2}^{2}\right)} \\
e_{3}^{*}=\frac{k\left[\sigma_{2}^{2}+a^{2} \sigma_{1}^{2}(k+\lambda a)\right]}{\mu\left(1+\rho \mu \sigma_{1}^{2}\right)\left(a \sigma_{1}^{2}+\sigma_{2}^{2}\right)} \\
U_{3}^{*}=\frac{k^{2}\left(a^{2} \sigma_{1}^{2}+\sigma_{2}^{2}\right)\left[\left(2 a \sigma_{1}^{2}+\sigma_{2}^{2}\right)\left(1+\rho \mu \sigma_{1}^{2}\right)-a^{2} \sigma_{1}^{2}\right](k+\lambda a)^{2}}{2 \mu\left(1+\rho \mu \sigma_{1}^{2}\right)^{2}\left(a \sigma_{1}^{2}+\sigma_{2}^{2}\right)^{2}}+\frac{k \lambda a\left(a^{2} \sigma_{1}^{2}+\sigma_{2}^{2}\right)}{\mu\left(1+\rho \mu \sigma_{1}^{2}\right)\left(a \sigma_{1}^{2}+\sigma_{2}^{2}\right)}+\lambda\left(r_{0}-a e_{0}\right)-\bar{w}^{\prime}
\end{gathered}
$$

By comparison, the following conclusion can be drawn.

Proposition 7. The project owner's profit in the incentive mechanism with constant total incentive intensity is higher than in the incentive mechanism which only considers the effort incentive.

Confirmation: Compare the project owner's profit in the condition of constant total incentive intensity with the condition of only considering effort incentive, the $d$-value is:

$$
U_{3}^{*}-U_{1}^{*}=\frac{k^{2} \sigma_{1}^{2}\left(a^{2} \sigma_{1}^{2}+\sigma_{2}^{2}\right)\left(a+\rho \mu a \sigma_{1}^{2}-a^{2}\right)}{2 \mu\left(1+\rho \mu \sigma_{1}^{2}\right)^{2}\left(a \sigma_{1}^{2}+\sigma_{2}^{2}\right)^{2}}+\frac{k \lambda a\left(a^{2} \sigma_{1}^{2}+\sigma_{2}^{2}\right)}{\mu\left(1+\rho \mu \sigma_{1}^{2}\right)\left(a \sigma_{1}^{2}+\sigma_{2}^{2}\right)}+\lambda\left(r_{0}-a e_{0}\right)>0
$$

Then, we can get $U_{3}^{*}>U_{1}^{*}$. 


\section{Numerical Analysis}

To enhance understanding, the application of the models is demonstrated with a numerical example. Suppose $k=10, \lambda=0.1, a=2$. Since $\lambda\left(r_{0}-a e_{0}\right)$ and $\bar{w}^{\prime}$ do not affect the results, assume $\lambda\left(r_{0}-a e_{0}\right)=0, \bar{w}^{\prime}=0$.

\subsection{Numerical Analysis of Incentive Mechanism with Reputational Concerns}

Assume $\sigma_{1}^{2}=1, \rho=1$, then Figure 1 is displayed through the numerical simulation. Figure 1 evaluates the relationship between the project owner's profit $\left(U_{2}\right)$ and the reputation variance $\left(\sigma_{2}^{2}\right)$ and the cost coefficient $(\mu)$. As depicted in Figure 1, the smaller the cost coefficient and the uncertainty of reputation evaluation are, the higher the profit of the project owner should be. Therefore, Figure 1 verifies Proposition 3, which also implies that the project owner should in fact increase the accuracy of reputation evaluation on the supplier, especially to those suppliers with lower effort cost.

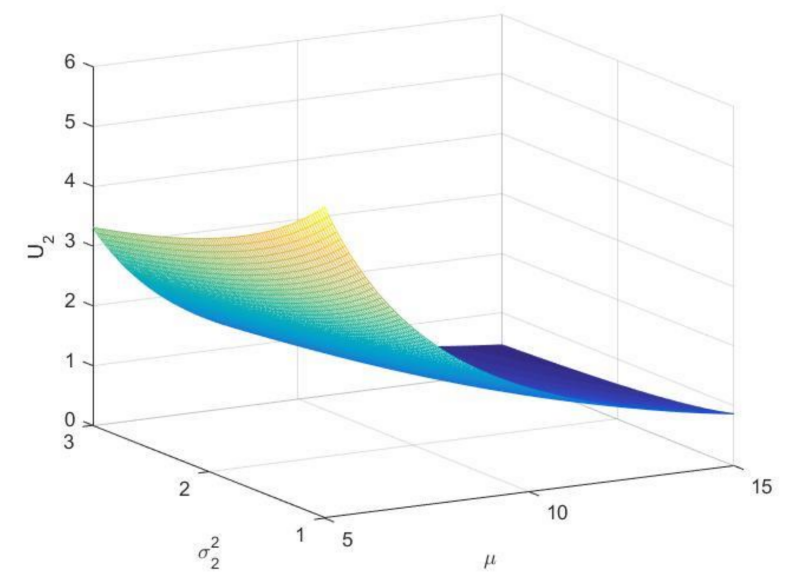

Figure 1. Effect of reputation variance $\sigma_{2}^{2}$ and cost coefficient $\mu$ on project owner's profit $U_{2}$.

Assume $\sigma_{1}^{2}=1, \mu=8$, then Figure 2 is displayed through the numerical simulation. Proposition 4 can be verified by Figure 2 .

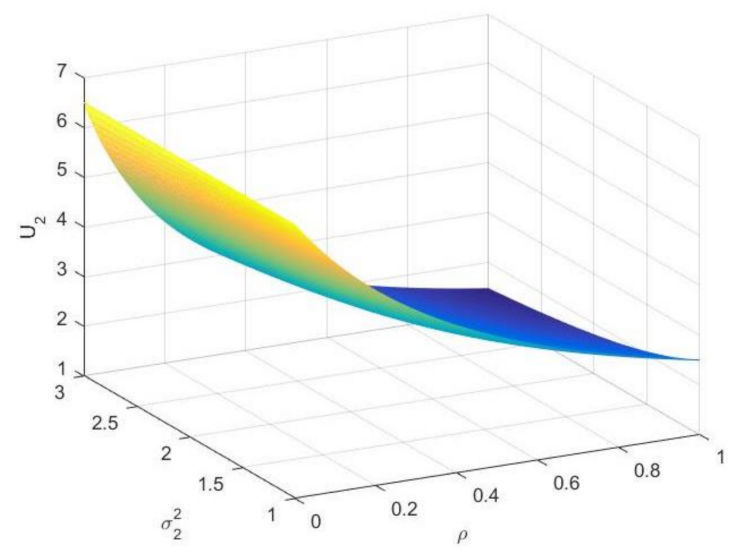

Figure 2. Effect of reputation variance $\sigma_{2}^{2}$ and risk evasion coefficient $\rho$ on owner's profit $U_{2}$.

Figure 2 indicates a reasonable conclusion although it is contrary to intuition. For instance, when the risk evasion coefficient of the supplier tends to infinity, which means the supplier is extremely sensitive to risk, it will be better to reduce the uncertainty of the reputation evaluation. However, just because of the excessive sensitivity that the supplier has to risk, the optimal incentive intensity on 
effort $\left(\beta_{e 2}^{*}\right)$ and on reputation $\left(\beta_{r 2}^{*}\right)$ tend to zero, therefore the project owner will only give the fixed payment to the supplier. At this moment, reducing the variance of reputation evaluation has little impact on the profit of the project owner.

\subsection{Numerical Analysis of Comparison of Incentive Mechanisms}

Assume $\sigma_{1}^{2}=1, \sigma_{2}^{2}=1, \rho=1 \mu=8$, a numerical example of the incentive mechanisms is shown in Table 1.

Table 1. The numerical example results of the incentive mechanisms.

\begin{tabular}{cccc}
\hline Incentive Mechanism & $\begin{array}{c}\text { Incentive Mechanism } \\
\text { without Reputational } \\
\text { Concerns }\end{array}$ & $\begin{array}{c}\text { Incentive Mechanism } \\
\text { with Reputational } \\
\text { Concerns }\end{array}$ & $\begin{array}{c}\text { Incentive Mechanism } \\
\text { with Constant Total } \\
\text { Incentive Intensity }\end{array}$ \\
\hline$\beta$ & 1.111 & $\left(\beta_{e}, \beta_{r}\right)=(0.785,1.554)$ & $\left(\beta_{e}, \beta_{r}\right)=(0.370,0.741)$ \\
$e$ & 0.139 & 0.490 & 0.232 \\
$U$ & 0.694 & 2.500 & 1.966 \\
\hline
\end{tabular}

Two findings can be drawn from Table 1: (1) Compared with the traditional incentive mechanism, when reputation incentive is considered, the supplier's effort will be significantly improved, so that the owner's payoff will also increase greatly. (2) Under the incentive mechanism with constant total incentive intensity, although the total incentive intensity is the same as that of incentive mechanism without reputational concerns, the supplier's effort and the owner's payoff all increase to a great extent. This means that, from the owner's perspective, better allocation of the constant total incentive intensity can motivate suppliers to invest more resources and efforts in the prefabricated production and improve the supplied product quality, so that the owner's profit can be improved.

The $d$-values of different incentive mechanisms are investigated in the following parts. Here, if $\sigma_{1}^{2}$ are not the host variables, then assume $\sigma_{1}^{2}=1$. If $\sigma_{2}^{2}$ are not the host variables, then assume $\sigma_{2}^{2}=1$. The values of other parameters will be the same as above.

Figure 3 is displayed through the numerical simulation, which further evaluates the relationships between the profit $d$-value of two incentive contracts and the variance of effort $\left(\sigma_{1}^{2}\right)$ and reputation $\left(\sigma_{2}^{2}\right)$.

As depicted in Figure 3, when the uncertainty of reputation evaluation is kept the same, the profit $d$-value is correlated positively with the uncertainty of effort observation. On the contrary, when the uncertainty of effort observation is kept the same, the profit $d$-value is correlated negatively with the uncertainty of reputation evaluation. Figure 3 also indicates that, as compared to the uncertainty of effort observation, if the reputation evaluation is more accurate, which means the uncertainty of reputation evaluation is lower, then the reputation incentive will be more effective. Therefore, it is good for the project owner to introduce the reputation incentive in the incentive contract.

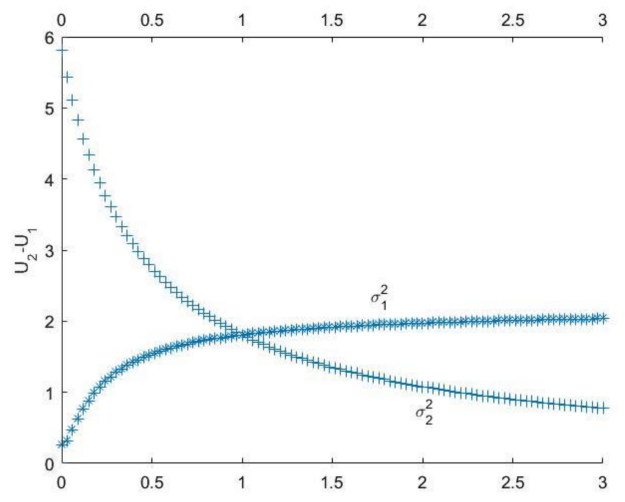

Figure 3. The relationships between profit $d$-value $\left(U_{2}^{*}-U_{1}^{*}\right)$ and the variances $\left(\sigma_{1}^{2}, \sigma_{2}^{2}\right)$. 
Figure 4 is displayed through the numerical simulation, which further evaluates the relationships between the profit $d$-value of two different incentive mechanisms and the variance of effort $\left(\sigma_{1}^{2}\right)$ and reputation $\left(\sigma_{2}^{2}\right)$.

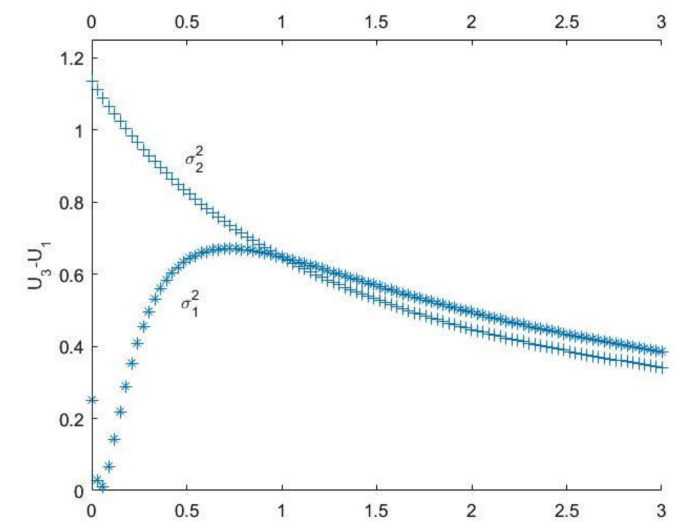

Figure 4. The relationships between profit $d$-value $U_{3}^{*}-U_{1}^{*}$ and the variances $\left(\sigma_{1}^{2}, \sigma_{2}^{2}\right)$.

Figure 4 implies that the owner can improve his profit by reducing the uncertainty of reputation evaluation. Different from Figure 3, Figure 4 indicates that, when the uncertainty of effort observation increases to a certain extent, profit $d$-value decreases. The reason is that, when $\sigma_{1}^{2}$ is large enough, the optimal incentive intensity in the incentive mechanism without reputational concerns $\left(\beta_{e 1}^{*}\right)$ will tend to zero, namely $C \rightarrow 0$, then the project owner cannot improve its profit through reputation incentive under the limitation of total incentive intensity. Therefore, when there is a large uncertainty in effort observation, the project owners will lose the opportunity to use reputation information to better motivate the supplier if they insist on adopting the incentive mechanism with constant total incentive intensity.

\subsection{Management Insights}

Although prefabrication is increasingly adopted in mega projects, there are still complexities during production process, such as high technical requirements, tight production duration, high quality standards and large project quantities. Therefore, it is difficult for designers and builders to provide such high quality and large quantity products at technology level. The manufacturing equipment renewal fee, R\&D fee, plant construction fee and training fees would greatly increase the cost of prefabrication production. Therefore, the responsibility for the construction of mega projects, such as technology and design, would not only been taken by designers and builders, but also the owner of the mega project should take these responsibilities. The incentives need to be introduced in the prefabrication production. It can be seen from the numerical analysis that the performance can be improved through the incentive mechanism, while multiple factors also affect the performance. Therefore, the following recommendations for suppliers and the owner can be drawn, according to the analysis.

For the suppliers, they need try their best to improve their output capacity, reduce their effort cost, as well as reduce their risk evasion degree to receive high incentives. For the owner, the recommendations are as follows. Firstly, the owner needs to compare the key components manufacturing suppliers from multiple levels and fields, and choose the suppliers with good performance, high technical level, rich experience, and high reputation. Secondly, the owner needs carry out price subsidies for the supplier in the contract, for the purchase of automated equipment and the amortization of plant construction costs, to achieve incentives for the prefabrication production [35]. Thirdly, the owner needs to introduce reputation incentive in prefabrication production with their maximum acceptable incentive intensity, and strengthen the communication and supervision with the 
suppliers, thereby the effort observation and the reputation evaluation can be more accurate, then the reputation incentive can be more effective. Finally, the owner can transform the gaming relationship between the owner and the suppliers into a partnership, and improve the suppliers' qualifications and capabilities, core competitiveness and its reputation in the industry by guiding and nurturing the suppliers through the equipment improvement and technological innovation of the project, which is one of the most important reputation incentives for the suppliers.

\section{Conclusions}

Since prefabricated production plays an important role in the construction of mega projects, it is one of the key responsibilities for the project owner to coordinate and cultivate the suppliers to achieve sustainability project management goals. Therefore, this study considered and compared three different incentive mechanism from the perspective of the project owner: explicit incentive model with no reputational concerns, incentive mechanism with reputational concerns and incentive mechanism with constant total incentive intensity. The results show that, under the incentive mechanism with reputational concerns, the incentive intensity is not only closely related to the variance of the incentive target itself, but is also influenced by the variance of another incentive target. The level of productive effort of the supplier and the profit of the project owner is correlated positively with the effort coefficient and the reputation coefficient, but negatively with the cost coefficient, the risk evasion coefficient, and the variance of the incentive target. In addition, when reducing the variance of the reputation evaluation, different cost coefficients and risk evasion coefficients of supplier have different effects on the owner's profit. By contrast, adding the reputation incentive could improve the supplier's effort and the project owner's profit effectively. However, the incentive intensity from the owner will also increase. Therefore, the study further investigated the problem that the project owner does not want to increase the incentive intensity when the reputation incentive is considered. The result indicates that, by reallocating part of the incentive intensity to reputation incentive, the incentive mechanism with constant total incentive intensity is also valid.

The findings provide useful suggestions for the owner. On the one hand, this research suggests the owner adopt an incentive mechanism with reputational concerns; the incentive intensity depends on the upper limit which the owner is willing to accept. On the other hand, to better realize the advantages generated by considering the reputation incentive, the project owner should decrease both the uncertainty of reputation evaluation and the uncertainty in effort observation for the suppliers, especially to those suppliers with lower effort cost. Therefore, the owner should reduce the information asymmetry and receive more information from the suppliers, so that they can make better decisions to motivate the prefabrication practices. In future research, more heterogeneous suppliers will be considered to improve the incentive mechanisms.

Acknowledgments: This work is supported by Major Program of National Natural Science Foundation of China (71390520 and 71390521), National Natural Science Foundation of China (71571098, 71732003, 71671088, 71671078, and 71701090), Nanjing University Innovation and Creative Program for Ph.D. candidate (2016010), and the program B for Outstanding Ph.D. candidate of Nanjing University (201701B009 and 201701B010).

Author Contributions: Qianqian Shi and Jianbo Zhu designed the study and completed the paper in English together. Marcel Hertogh and Zhaohan Sheng provided useful research advice and revised the manuscript.

Conflicts of Interest: The authors declare no conflict of interest.

\section{References}

1. He, Q.; Luo, L.; Hu, Y.; Chan, A.P. Measuring the complexity of mega construction projects in china-A fuzzy analytic network process analysis. Int. J. Proj. Manag. 2015, 33, 549-563. [CrossRef]

2. Lu, Y.; Luo, L.; Wang, H.; Le, Y.; Shi, Q. Measurement model of project complexity for large-scale projects from task and organization perspective. Int. J. Proj. Manag. 2015, 33, 610-622. [CrossRef]

3. Hertogh, M.; Westerveld, E. Playing with Complexity. Management and Organisation of Large Infrastructure Projects; Erasmus University Rotterdam: Rotterdam, The Netherlands, 2010. 
4. Kivilä, J.; Martinsuo, M.; Vuorinen, L. Sustainable project management through project control in infrastructure projects. Int. J. Proj. Manag. 2017, 35, 1167-1183. [CrossRef]

5. Jaillon, L.; Poon, C.-S. Sustainable construction aspects of using prefabrication in dense urban environment: A Hong Kong case study. Constr. Manag. Econ. 2008, 26, 953-966. [CrossRef]

6. Aarseth, W.; Ahola, T.; Aaltonen, K.; Økland, A.; Andersen, B. Project sustainability strategies: A systematic literature review. Int. J. Proj. Manag. 2017, 35, 1071-1083. [CrossRef]

7. Said, H. Prefabrication best practices and improvement opportunities for electrical construction. J. Constr. Eng. Manag. 2015, 141, 04015045. [CrossRef]

8. Chen, Y.; Okudan, G.E.; Riley, D.R. Sustainable performance criteria for construction method selection in concrete buildings. Autom. Constr. 2010, 19, 235-244. [CrossRef]

9. Tam, C.; Tam, V.W.; Chan, J.K.; Ng, W.C. Use of prefabrication to minimize construction waste-a case study approach. Int. J. Constr. Manag. 2005, 5, 91-101. [CrossRef]

10. Blismas, N.; Pasquire, C.; Gibb, A. Benefit evaluation for off-site production in construction. Constr. Manag. Econ. 2006, 24, 121-130. [CrossRef]

11. Rahman, M.M. Barriers of implementing modern methods of construction. J. Manag. Eng. 2013, 30, 69-77. [CrossRef]

12. Mao, C.; Shen, Q.; Pan, W.; Ye, K. Major barriers to off-site construction: The developer's perspective in china. J. Manag. Eng. 2015, 31. [CrossRef]

13. Hong, J.; Shen, G.Q.; Li, Z.; Zhang, B.; Zhang, W. Barriers to promoting prefabricated construction in china: A cost-benefit analysis. J. Clean. Prod. 2018, 172, 649-660. [CrossRef]

14. Tam, W.Y.V.; Fung, W.H.; Sing, C.P.; Ogunlana, S.O. Best practice of prefabrication implementation in the Hong Kong private and public sector. J. Clean. Prod. 2015, 109, 216-231. [CrossRef]

15. Mao, C.; Xie, F.; Hou, L.; Wu, P.; Wang, J.; Wang, X. Cost analysis for sustainable off-site construction based on a multiple-case study in china. Habitat Int. 2016, 57, 215-222. [CrossRef]

16. Khalili, A.; Chua, D. Integrated prefabrication configuration and component grouping for resource optimization of precast production. J. Constr. Eng. Manag. 2013, 140, 04013052. [CrossRef]

17. Isaac, S.; Bock, T.; Stoliar, Y. A methodology for the optimal modularization of building design. Autom. Constr. 2016, 65, 116-124. [CrossRef]

18. Xue, H.; Zhang, S.J.; Su, Y.K.; Wu, Z.Z. Factors affecting the capital cost of prefabrication-a case study of china. Sustainability 2017, 9, 22. [CrossRef]

19. Zhang, W.; Zhang, J.; Wang, H.; Zhou, H. Supplier development and its incentives in infrastructure mega-projects: A case study on Hong Kong-zhuhai-macao bridge project. Front. Eng. 2018, 5, 88-97.

20. Dowling, G.R. Defining and measuring corporate reputations. Eur. Manag. Rev. 2016, 13, 207-223. [CrossRef]

21. Fombrun, C.; Shanley, M. What's in a name? Reputation building and corporate strategy. Acad. Manag. J. 1990, 33, 233-258. [CrossRef]

22. Marnewick, C. Information system project's sustainability capabality levels. Int. J. Proj. Manag. 2017, 35, 1151-1166. [CrossRef]

23. Robichaud, L.B.; Anantatmula, V.S. Greening project management practices for sustainable construction. J. Manag. Eng. 2010, 27, 48-57. [CrossRef]

24. Wang, T.; Wang, J.; Wu, P.; Wang, J.; He, Q.; Wang, X. Estimating the environmental costs and benefits of demolition waste using life cycle assessment and willingness-to-pay: A case study in shenzhen. J. Clean. Prod. 2018, 172, 14-26. [CrossRef]

25. Song, Y.; Tan, Y.; Song, Y.; Wu, P.; Cheng, J.C.P.; Kim, M.J.; Wang, X. Spatial and temporal variations of spatial population accessibility to public hospitals: A case study of rural-urban comparison. GISci. Remote Sens. 2018, 55, 1-27. [CrossRef]

26. Silvius, A.; Schipper, R.P. Sustainability in project management: A literature review and impact analysis. Soc. Bus. 2014, 4, 63-96. [CrossRef]

27. Silvius, A.G.; Kampinga, M.; Paniagua, S.; Mooi, H. Considering sustainability in project management decision making; an investigation using q-methodology. Int. J. Proj. Manag. 2017, 35, 1133-1150. [CrossRef]

28. Martens, M.L.; Carvalho, M.M. Key factors of sustainability in project management context: A survey exploring the project managers' perspective. Int. J. Proj. Manag. 2017, 35, 1084-1102. [CrossRef] 
29. Marcelino-Sádaba, S.; González-Jaen, L.F.; Pérez-Ezcurdia, A. Using project management as a way to sustainability. From a comprehensive review to a framework definition. J. Clean. Prod. 2015, 99, 1-16. [CrossRef]

30. Verrier, B.; Rose, B.; Caillaud, E. Lean and green strategy: The lean and green house and maturity deployment model. J. Clean. Prod. 2016, 116, 150-156. [CrossRef]

31. Jaillon, L.; Poon, C. Life cycle design and prefabrication in buildings: A review and case studies in Hong Kong. Autom. Constr. 2014, 39, 195-202. [CrossRef]

32. Jaillon, L.; Poon, C.S. Design issues of using prefabrication in Hong Kong building construction. Constr. Manag. Econ. 2010, 28, 1025-1042. [CrossRef]

33. Jeong, J.G.; Hastak, M.; Syal, M.; Hong, T. Internal relationship modeling and production planning optimization for the manufactured housing. Autom. Constr. 2011, 20, 864-873. [CrossRef]

34. Altaf, M.S.; Bouferguene, A.; Liu, H.; Al-Hussein, M.; Yu, H. Integrated production planning and control system for a panelized home prefabrication facility using simulation and rfid. Autom. Constr. 2018, 85, 369-383. [CrossRef]

35. Shi, Q.; Zhu, J.; Li, Q. Cooperative evolutionary game and applications in construction supplier tendency. Complexity 2018, 2018, 8401813. [CrossRef]

36. Feng, T.; Tai, S.; Sun, C.; Man, Q. Study on cooperative mechanism of prefabricated producers based on evolutionary game theory. Math. Probl. Eng. 2017, 2017, 1676045. [CrossRef]

37. Wu, G.; Zuo, J.; Zhao, X. Incentive model based on cooperative relationship in sustainable construction projects. Sustainability 2017, 9, 1191. [CrossRef]

38. Meng, X.; Gallagher, B. The impact of incentive mechanisms on project performance. Int. J. Proj. Manag. 2012, 30, 352-362. [CrossRef]

39. Suprapto, M.; Bakker, H.L.; Mooi, H.G.; Hertogh, M.J. How do contract types and incentives matter to project performance? Int. J. Proj. Manag. 2016, 34, 1071-1087. [CrossRef]

40. Kerkhove, L.-P.; Vanhoucke, M. Incentive contract design for projects: The owner's perspective. Omega 2016, 62, 93-114. [CrossRef]

41. Rose, T.; Manley, K. Motivation toward financial incentive goals on construction projects. J. Bus. Res. 2011, 64, 765-773. [CrossRef]

42. Love, P.E.; Davis, P.R.; Chevis, R.; Edwards, D.J. Risk/reward compensation model for civil engineering infrastructure alliance projects. J. Constr. Eng. Manag. 2010, 137, 127-136. [CrossRef]

43. Kwon, H.D.; Lippman, S.A.; Tang, C.S. Sourcing decisions of project tasks with exponential completion times: Impact on operating profits. Int. J. Prod. Econ. 2011, 134, 138-150. [CrossRef]

44. Chan, D.W.; Lam, P.T.; Chan, A.P.; Wong, J.M. Achieving better performance through target cost contracts: The tale of an underground railway station modification project. Facilities 2010, 28, 261-277. [CrossRef]

45. Karle, H.; Schumacher, H.; Staat, C. Signaling quality with increased incentives. Eur. Econ. Rev. 2016, 85, 8-21. [CrossRef]

46. Hosseinian, S.M.; Carmichael, D.G. Optimal incentive contract with risk-neutral contractor. J. Constr. Eng. Manag. 2012, 139, 899-909. [CrossRef]

47. Bubshait, A.A. Incentive/disincentive contracts and its effects on industrial projects. Int. J. Proj. Manag. 2003, 21, 63-70. [CrossRef]

48. Rose, T.M.; Manley, K. Financial incentives and advanced construction procurement systems. Proj. Manag. J. 2010, 41, 40-50. [CrossRef]

49. Fu, R.; Subramanian, A.; Venkateswaran, A. Project characteristics, incentives, and team production. Manag. Sci. 2015, 62, 785-801. [CrossRef]

50. Sommer, S.C.; Loch, C.H. Incentive contracts in projects with unforeseeable uncertainty. Prod. Oper. Manag. 2009, 18, 185-196. [CrossRef]

51. Tang, C.S.; Zhang, K.; Zhou, S.X. Incentive contracts for managing a project with uncertain completion time. Prod. Oper. Manag. 2015, 24, 1945-1954. [CrossRef]

52. Yang, K.; Zhao, R.; Lan, Y. Impacts of uncertain project duration and asymmetric risk sensitivity information in project management. Int. Trans. Oper. Res. 2016, 23, 749-774. [CrossRef]

53. Fama, E.F. Agency problems and the theory of the firm. J. Political Econ. 1980, 88, 288-307. [CrossRef]

54. Kreps, D.M.; Wilson, R. Sequential equilibria. Econ. J. Econ. Soc. 1982, 50, 863-894. [CrossRef] 
55. Kreps, D.M.; Milgrom, P.; Roberts, J.; Wilson, R. Rational cooperation in the finitely repeated prisoners' dilemma. J. Econ. Theory 1982, 27, 245-252. [CrossRef]

56. Milgrom, P.; Roberts, J. Limit pricing and entry under incomplete information: An equilibrium analysis. Econometrica 1982, 50, 443-459. [CrossRef]

57. Healy, P.J. Group reputations, stereotypes, and cooperation in a repeated labor market. Am. Econ. Rev. 2007, 97, 1751-1773. [CrossRef]

58. Chi, H.; Hou, J. Study on logistics project team member's incentive mechanism based on reputation. In Iclem 2010: Logistics for Sustained Economic Development: Infrastructure, Information, Integration; American Society of Civil Engineers: Reston, VA, USA, 2010; pp. 423-430.

59. Huang, C.; Zhang, Y.; Lai, C. A mathematical model of communication with reputational concerns. Discret. Dyn. Nat. Soc. 2016, 2016, 6507104. [CrossRef]

60. Wagner, S.M.; Coley, L.S.; Lindemann, E. Effects of suppliers'reputation on the future of buyer-supplier relationships: The mediating roles of outcome fairness and trust. J. Supply Chain Manag. 2011, 47, $29-48$. [CrossRef]

61. Lu, W.; Zhang, L.; Pan, J. Identification and analyses of hidden transaction costs in project dispute resolutions. Int. J. Proj. Manag. 2015, 33, 711-718. [CrossRef]

62. Chen, J.-H.; Ma, S.-H. A dynamic reputation incentive model in construction supply chain. In Proceedings of the ICMSE 2008 15th Annual International Conference on Management Science and Engineering, Long Beach, CA, USA, 10-12 September 2008; pp. 385-392.

63. Lai, X.; Wu, G.; Shi, J.; Wang, H.; Kong, Q. Project value-adding optimization of project-based supply chain under dynamic reputation incentives. Int. J. Simul. Model. 2015, 14, 121-133. [CrossRef]

(C) 2018 by the authors. Licensee MDPI, Basel, Switzerland. This article is an open access article distributed under the terms and conditions of the Creative Commons Attribution (CC BY) license (http:/ / creativecommons.org/licenses/by/4.0/). 